\title{
Commentary: Can we move beyond aortic size, using real-time analysis of aortic tissue, to more precisely guide therapy for patients with bicuspid aortic valves?
}

\author{
Stephen H. McKellar, MD, MSc
}

\author{
From the Division of Cardiothoracic Surgery, University of Utah School of Medicine, Salt Lake City, Utah. \\ Disclosures: Author has nothing to disclose with regard to commercial support. \\ Received for publication Sept 12, 2019; revisions received Sept 12, 2019; accepted for publication Sept 13, 2019; \\ available ahead of print Sept 20, 2019. \\ Address for reprints: Stephen H. McKellar, MD, MSc, 30 N 1900 E 3C 127 SOM, Salt Lake City, UT 84132 \\ (E-mail: stephen.mckellar@hsc.utah.edu). \\ J Thorac Cardiovasc Surg 2020;160:e259 \\ $0022-5223 / \$ 36.00$ \\ Copyright (C) 2019 by The American Association for Thoracic Surgery \\ https://doi.org/10.1016/j.jtcvs.2019.09.014
}

I congratulate Chim and co-authors ${ }^{1}$ for their article in this issue of the Journal, "Bicuspid valve aortopathy is associated with distinct patters on matric degradation." In this elegant study, they performed mechanical and microstructural analyses of aortic tissue from patients with aneurysms associated with bicuspid aortic valves (BAV-A) compared with patients with degenerative aneurysms (and tricuspid valves) (DA), and control aortic tissue obtained from aortic punch biopsies during coronary artery bypass grafting. They used novel micromechanical assays and basic histological assays to test the hypothesis that BAV-A tissue would have a unique mechanical and structural signature compared with DA and control aortic tissues.

They found that 1) BAV-A tissue was stiffer than the tissue in the DA and control groups, 2) the 2 aneurysm groups (BAV-A and DA) had higher collagen content compared with controls, and 3) both aneurysm groups had a distinct distribution of elastin location in the aneurysm groupsspecifically, less elastin near the intima and adventitia and more elastin in the media-compared with controls.

These results are encouraging, as they provide further evidence that the BAV-A and DA are different and that combining them for clinical research purposes and clinical guidelines may be inappropriate. In addition, these results provide additional evidence suggesting that other criteria besides aortic size could potentially be used to help clinicians guide therapy. For instance, knowledge of tissue properties could help surgeons decide whether a concomitant

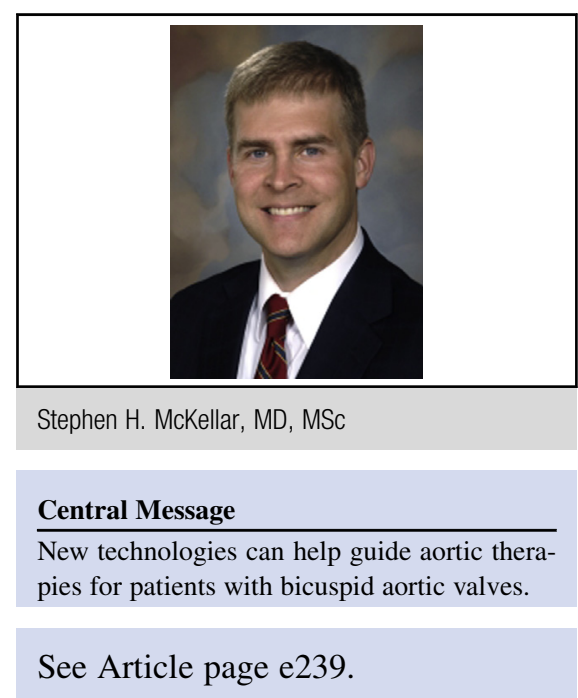

ascending aortic replacement at the time of aortic valve replacement (AVR) is indicated.

Although these data are preliminary, and much more research is needed, one wonders if either the mechanical property tests used here (ie, oscillatory nanoindentation) or analyses of collagen content and distribution could be performed in real time in the operating room or frozen section pathology laboratory to guide intraoperative decision making. If the results from such assays could be obtained in the time it takes to perform an AVR, then data showing increased aortic stiffness or abnormal collagen distribution could direct the surgeon to proceed with concomitant ascending aortic replacement. Such point-of-care testing tools could help solve the age-old dilemma of predicting the fate of the ascending aorta in patients with BAV.

\section{Reference}

1. Chim YH, Davies HA, Mason D, Nawaytou O, Field M, Madine J, et al. Bicuspid aortic valve aortopathy is associated with distinct patterns of matrix degradation. $J$ Thorac Cardiovasc Surg. 2020;160:e239-57. 